\title{
Chronic fatigue after a night of work in Serbia (our experience)
}

BY LJILJANA GVOZDENOVIĆ, TATJANA BATAK, GORICA MALIŠANOVIĆ

Working during the night, especially with geriatric patients, has a detrimental effect on the circadian rhythm. (1) This study was approved by the Ethics Committee and Commission for Examining Ethics. The sample was randomly formed and consisted of 1200 nurses. In order to meet ethical standards in research, subjects voluntarily signed the consent form to join the study. The study group consisted of 600 nurses working the night shift with geriatric patients. The control group consisted of 600 nurses working the eight-hour day shift. As a survey instrument, two questionnaires were used. The first questionnaire was originally made for the purpose of this study and collected demographic and sociological data about individual respondents (gender, age, years of service, working night shift, marital status, number of children, material and social satisfaction). A standardized questionnaire, Piper Fatigue Scale (PFS; $\alpha=0.85$ ), collected data on subjective assessment of the level of fatigue. The Piper Fatigue Scale consists of 22 questions and provides answers on a ten-point scoring scale, which best describe quality and intensity of fatigue felt in the past seven days. Obtaining a higher score indicates greater intensity of fatigue. Student's t-test and Pearson's chi square test were used to assess demographic and sociological data, whereas Pearson's correlation coefficient was used to test the effect of night shift on the level of fatigue. In terms of demographic and sociological characteristics of each sample, females accounted for the majority of night shift subjects $(p<0.001)$ and most of the day shift subjects $(\mathrm{p}<\mathrm{o.001})$. Generally, night shift respondents were younger in comparison to day shift respondents, and this difference is statistically significant $(\mathrm{p}<0.001)$. Respondents were divided into 3 categories according to the length of service: I-category (o-10 years), II-category (11-21 years), and III-category (> 21 years). Night shift workers had fewer years of service 
than day shift workers. This difference is statistically significant for all three categories of service $(\mathrm{p}<0.01)$. In relation to marital status, $180(30 \%)$ night shift and $370(61.7 \%)$ day shift respondents were married $(\mathrm{p}<0.001) .360(60 \%)$ night shift and 160 (26.7\%) day shift workers were not married $(\mathrm{p}<0.001)$. Sixty $(10 \%)$ shift and $70(11.7 \%)$ non-shift workers were divorced, and there was no statistically significant difference between them $(\mathrm{p}>0.05)$. Day shift workers were more satisfied with their social life than night shift workers and this difference is statistically significant $(\mathrm{p}<0.01)$. Day shift workers often perceived subjective fatigue on a level of $1-6$, while perception of fatigue for night shift workers was on a level between $6-10$. The biggest difference between the respondents was recorded in the perception of fatigue at level $8(\mathrm{p}>0.001)$. Involvement in work shifts positively correlated with each of the 22 questionnaire items in PFS, with an increased level of fatigue in nurses (Pearson correlation coefficient, $p>0.001$ ). A survey by the Canadian Nurses Association (CNA, 2010) states that 25.8\% of nurses resigned due to symptoms of fatigue in the workplace, $20.2 \%$ retired, and as many as $25.6 \%$ of them changed their profession for the same reason. (2) Our findings confirm the fact that during their professional careers nurses are excessively exposed to stressful situations and hardworking patterns are integral parts of their daily routine. (3-5) Demographics, working characteristics, and family structure are associated with chronic fatigue between shifts in nursing personnel. The modification of shift schedules according to individual needs and preferences is necessary for the reduction of chronic fatigue and maintenance of personal satisfaction.

Promotion and implementation of active rest breaks during working hours between shifts could help reduce mental and physical fatigue of nurses.

\section{References}

1. Cordova PB, Phibbs CS, Bartel AP, Stone PW. Twenty-four/seven: a mixed-method systematic review of the off-shift literature. J Adv Nurs 2012;68(7):1454-68.

2. Sharma A, Verma A, Malhotra D. Job Performance and Chronic Fatigue Syndrome in Nurses. Asian Social Science 2010;6(12):167-71.

3. Barker LM, Nussbaum MA. Fatigue, performance and the work environment: a survey of registered nurses. J Adv Nur 2011;67(6):1370-82.

4. Silva AA, Rotenberg L, Fischer FM. Nursing work hours: individual needs versus working conditions. Rev Saúde Pública 2011;45(6):1117-26. 
SIGNA VITAE 2015; 10(1): 151 - 153

5. Geiger-Brown J, Rogers VE, Trinkoff AM, Kane RL, Bausell RB, Scharf SM. Sleep, sleepiness, fatigue, and performance of 12-hour-shift nurses. Chronobiol Int 2012;29(2):211-9.

Ljiljana Gvozdenović, Tatjana Batak, Gorica Mališanović

Clinical Center of Vojvodina, Faculty of Medicine, Novi Sad, Serbia Corresponding author:

Ljiljana Gvozdenović

Clinical Center of Vojvodina

Hajduk Veljkova $1-7$.

Novi Sad, Serbia

Phone: +38163-529-409

Fax: +38121-423-902

E-mail: profgvozdenovic2010@hotmail.com 